\title{
COLONIZATION VERSUS INFECTION OF THE LOWER RESPIRATORY TRACT: A CLINICAL STUDY
}

\author{
Sudin Koshy1, Ashish Jithendranath ${ }^{2}$
}

${ }^{1}$ Associate Professor, Department of Pulmonology, Sree Gokulam Medical College and Research Foundation, Thiruvananthapuram. ${ }^{2}$ Assistant Professor, Department of Microbiology, Sree Gokulam Medical College and Research Foundation, Thiruvananthapuram.

\section{ABSTRACT}

\section{BACKGROUND}

The clinicians often get organisms in culture of respiratory secretions. In certain clinical situations it is difficult to differentiate whether it is a true pathogen or colonizer. Distinguishing colonization from infection is an important factor in making the correct diagnosis in a variety of conditions. Microbiological specimens obtained respiratory secretions need careful interpretation. The study is done to differentiate between colonization versus infection of the lower respiratory tract.

\section{METHODS}

Retrospective analysis of data was carried out to differentiate between the colonizer and the true pathogens from the organisms grown from the culture of respiratory secretions.

\section{RESULTS}

Using clinical and radiological correlation, the isolated organisms were classified as true pathogen or colonizer. The study showed that $75.6 \%$ of the organisms obtained from the sputum sample were true pathogens, while $61.5 \%$ of organisms obtained from suction tip culture were colonizers; $72.2 \%$ of patients who had pathogenic organism in culture had radiological shadow.

\section{CONCLUSION}

With good quality microbiology specimen and meticulous clinical and radiological correlation, it is possible to differentiate between colonizers from pathogenic organisms. Correctly identifying colonizer will prevent clinicians from unnecessary use of antibiotics.

\section{KEYWORDS}

Colonization versus Infection, Lower Respiratory Pathogen.

HOW TO CITE THIS ARTICLE: Koshy S, Jithendranath A. Colonization versus infection of the lower respiratory tract: a clinical study. J. Evolution Med. Dent. Sci. 2016;5(58):3995-3997, DOI: 10.14260/jemds/2016/914

\section{INTRODUCTION}

The clinicians often get organisms in culture of respiratory secretions. Sometimes it is difficult to differentiate whether it is a true pathogen or colonizer. Distinguishing colonization from infection is an important factor in making the correct diagnosis in a variety of conditions.

Colonization implies that the patient has a sufficiently high concentration of organisms at a site that they can be detected, yet the organism is causing no signs or symptoms. This differs from contamination, where the organism was never present in the site from which it has been detected, but was introduced into the specimen from another site or from contamination in the laboratory. ${ }^{1}$

Most organisms which colonize are harmless commensals and are best left alone. They may in fact prevent invasion by pathogens. Microbiological specimens obtained respiratory secretions need careful interpretation. ${ }^{2}$ We need to differentiate between colonizer and pathogenic bacterial infection, so that we do not unnecessarily give antibiotics to the patient.

Financial or Other, Competing Interest: None.

Submission 24-05-2016, Peer Review 17-06-2016,

Acceptance 24-06-2016, Published 19-07-2016.

Corresponding Author:

Dr. Sudin Koshy,

TC 10/731(12), B3 Villa,

Sowparnika Projects,

Opposite St. Thomas School,

Mukkolackal P.O., Mannanthala,

Thiruvananthapuram, Kerala.

E-mail: drsudinkoshy@gmail.com

DOI: $10.14260 /$ jemds $/ 2016 / 914$

\section{OBJECTIVES}

To differentiate between the colonizer and the true pathogens from the organisms grown from the culture of respiratory secretions.

\section{MATERIAL AND METHODS \\ Study Design \\ Retrospective analysis of data.}

\section{Study Period}

Oct. to Nov. 2015.

\section{Study Setting}

Sree Gokulam Medical College and Research Foundation, Venjaramoodu.

\section{Study Population}

Patients admitted in Sree Gokulam Medical College Hospital, who have a positive bacteriological culture from respiratory secretions.

\section{METHODOLOGY}

Data of the respiratory samples sent to the microbiology lab for gram staining, culture and identification and antibiotic sensitivity were collected. Patients who had a positive bacteriological culture from respiratory secretions were included in the study.

Details of presenting complaints and clinical findings on admission and discharge were collected from records. X-ray of all the patients were reviewed by the pulmonologist. 
All the sputum samples were cultured on Blood agar, Chocolate agar and MacConkey agar. The colonies were then identified using biochemical tests.

Antibiotic sensitivity was done following CLSI 2015 guidelines.

\section{RESULTS}

Total number of patients studied $=54$

\begin{tabular}{|l|c|c|}
\hline \multirow{2}{*}{ Gender } & Female & $20(37.0)$ \\
\cline { 2 - 3 } & Male & $34(63.0)$ \\
\hline
\end{tabular}

Male patients constituted $63 \%$ of the study population.

\begin{tabular}{|c|c|c|}
\hline \multirow{2}{*}{ Age Group } & 60 yrs. \& Below 60 yrs. & $22(40.7)$ \\
\cline { 2 - 3 } & Above 60 Yrs. & $32(59.3)$ \\
\hline
\end{tabular}

$59.3 \%$ of the patients were above the age of 60 .

\begin{tabular}{|c|c|c|}
\hline \multirow{2}{*}{ Sample } & Suction Tip & $13(24.1)$ \\
\cline { 2 - 3 } & Sputum & $41(75.9)$ \\
\hline
\end{tabular}

Sputum sample was used for culture in $75.9 \%$ of the patients.

Using clinical and radiological correlation, the isolated organisms were classified as true pathogen or colonizer.

\begin{tabular}{|c|c|c|}
\hline Colonizer (\%) & Pathogen (\%) & Total \\
\hline $18(33.3)$ & $36(66.6)$ & 54 \\
\hline
\end{tabular}

\begin{tabular}{|c|c|c|c|c|}
\hline $\begin{array}{c}\text { Sample } \\
\text { Source }\end{array}$ & $\begin{array}{c}\text { Colonizer } \\
\text { (\%) }\end{array}$ & $\begin{array}{c}\text { Pathogen } \\
\mathbf{( \% )}\end{array}$ & $\begin{array}{c}\text { Total } \\
(\mathbf{n = 5 4 )}\end{array}$ & P value \\
\hline Suction tip & $8(61.5)$ & $5(38.5)$ & 13 & $\mathbf{0 . 0 3 2 5}$ \\
\hline Sputum & $10(24.4)$ & $31(75.6)$ & 41 & \\
\hline
\end{tabular}

The study showed that $75.6 \%$ of the organisms obtained from the sputum sample were true pathogens, while $61.5 \%$ of organisms obtained from suction tip culture were colonizers.

\begin{tabular}{|c|c|c|c|c|}
\hline $\begin{array}{c}\text { X-Ray } \\
\text { Findings }\end{array}$ & Colonizer & $\begin{array}{c}\text { Pathogen } \\
\mathbf{( \% )}\end{array}$ & $\begin{array}{c}\text { Total } \\
(\mathbf{n = 5 4 )}\end{array}$ & $\begin{array}{c}\text { P } \\
\text { value }\end{array}$ \\
\hline No Findings & $16(88.9)$ & $10(27.8)$ & 26 & \multirow{2}{*}{$<0.001$} \\
\cline { 1 - 4 } $\begin{array}{c}\text { Lung Shadow } \\
\text { Present }\end{array}$ & $2(11.1)$ & $26(72.2)$ & 28 & \\
\hline & $18(100 \%)$ & $36(100 \%)$ & 54 & \\
\hline
\end{tabular}

$72.2 \%$ of patients who had pathogenic organism in culture had radiological shadow.

\section{DISCUSSION}

We live in a sea of microbes and so microbes would contaminate clinical specimens. ${ }^{3}$ We often get microbial cultures from respiratory secretions. For the practicing clinician, it is very important to differentiate whether the organism is a colonizer or pathogen.

The study has revealed that there is a high chance of culture growing a colonizer if the sample is obtained using suction tip instead of sputum sample. Clinical and radiological correlation is essential to ascertain whether the organism is a colonizer or pathogen. Giving antibiotics based on microbial culture alone can lead to misuse of antibiotic and development of drug resistant nosocomial organisms.
The normal upper and lower respiratory tract are not colonized by enteric gram-negative bacteria. When serious illness develops, both sites may harbour these organisms. Colonization at either site is more likely when the severity of illness increases. In critically ill patients, Pseudomonas species are the most common colonizing organisms, especially in the tracheobronchial tree. Many of the clinical conditions that favour colonization lead to an alteration in epithelial cell surface susceptibility to bacterial binding. ${ }^{4}$

The study showed that there is a high chance of culture growing a colonizer if the sample is obtained using suction tip instead of sputum sample ( $p$ value $<0.05$ ). If the patient has clinical features or radiological shadow, there is a high probability that the organism is pathogenic. With good quality microbiology specimen and clinic radiological correlation, it is possible to differentiate between colonizers from pathogenic organisms. Correctly identifying colonizer will prevent clinicians from unnecessary use of antibiotics.

Organisms isolated from respiratory secretions could be a contaminant, commensal or the true pathogen. The aetiological diagnosis is usually made based on semiquantitative cultures, but the Positive Predictive Value (PPV) of these colony counts is poor. The quality of the sputum sample may provide the clue to the aetiological agent if the sample is representative of the lower respiratory tract, i.e. has more than 25 PMN and less than 10 epithelial cells per low power field. This assures that the organisms seen are not oral commensals. $^{3}$

Many organisms present normally in the upper respiratory tract (e.g. Streptococcus pneumoniae) can cause pneumonia. Thus, the positive predictive value of Gram staining and the culture is low for predicting the cause of pneumonia if the sputum specimen is contaminated (i.e. not representative of the lower respiratory tract). Therefore, sputum specimens contaminated with upper respiratory tract contents as indicated by the presence of excessive squamous epithelial cells should be rejected and another specimen should be obtained if clinically indicated. ${ }^{5}$

In immunocompetent patient, organisms like Aspergillus and Candida in the sputum may represent colonizers and warrant therapy only if there is evidence of invasive disease such as imaging, histopathology or fungal antigenemia. ${ }^{3}$ If the organism is persistently isolated despite clinical improvement, the organism is most likely to be a colonizer. Continuous and systematic monitoring of the patient for systemic signs and symptoms is essential for distinguishing colonization from infection.

The clinician and the microbiologist should work synergistically to provide optimal care to patients. Open communication between them enables proper collection of specimens and allows appropriate testing to be done. This enables cost-effective and efficient reporting of microbiologic results, which in turn enables the clinician to treat the patient effectively and in a timely fashion. The clinician should also supply adequate clinical information to the laboratory to facilitate proper specimen processing and testing. ${ }^{5}$

\section{CONCLUSION}

With good quality microbiology specimen and meticulous clinical radiological correlation, it is possible to differentiate between colonizers from pathogenic organisms. Correctly 
identifying colonizer will prevent clinicians from unnecessary use of antibiotics.

\section{REFERENCES}

1. Robinson J. Colonization and infection of the respiratory tract: what do we know? Paediatr Child Health 2004;9(1):21-4.

2. Mandell, Douglas, Bennett's. Principles and practice of infectious diseases. $6^{\text {th }}$ edn. Philadelphia: Elsevier Churchill Livingstone 2005:3661pp.
3. Soman R. Colonization versus infection. Medicine Update 2008;18:330-3.

4. Niederman MS. Gram-negative colonization of the respiratory tract: pathogenesis and clinical consequences. Seminars in Respiratory Infections 1990;5(3):173-84.

5. Leung AK, Procop GW. The microbiology laboratory and the internist. Diseases Management 2010.

http://www.clevelandclinicmeded.com/medicalpubs/di seasemanagement/infectious-disease, August 2010. 